\title{
Dialogue between the individual and the state in contemporary Russian society
}

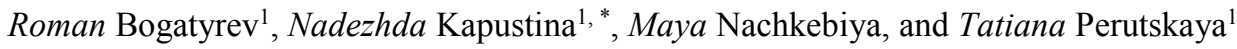 \\ ${ }^{1}$ Belgorod National Research University, 308015, Belgorod, Russia
}

\begin{abstract}
This article discusses the important aspects of the dialogue between the individual and the state in modern times. The importance of interaction between the government and the society in the modern world is one of the most urgent tasks for young researchers and for the society as a whole. Emphasizing the importance of strengthening and developing a democratic state governed by the rule of law, researchers identify a wide range of factors that have a direct impact on the positive and effective development of interaction between the government and the society. One such factor is the model of individual-state dialogue. The study of such a dialogue from an anthropological point of view will make it possible to highlight the most successful models of interaction between the society authorities to create effective management mechanisms that affect both the quality of citizens' life and the development of the state as a whole in a positive way. For a more detailed study of the models of building a dialogue between the individual and the state, it is necessary to consider the existing examples of interaction and analyze the historical aspects of the relationship between the society and the state. The modern practice of state and municipal governing strives to make the government more transparent and open to citizens, such a policy contributes to the maximum involvement of citizens in the public and political life of the state. The article also deals with the issues of involving citizens in the social and political life of the society; it discusses the motivational measures and the policy of the state in the field of engaging citizens in interaction and establishment of a meaningful, effective dialogue between the society and the state.
\end{abstract}

\section{Introduction}

In history a dialogue between the individual and the state has generally taken a place in between negative acts of terrorism, extremism, antipathy towards power and severe riots, coups and revolutions. If one of the parties did not enter a dialogue to resolve the conflict or the dialogue did not lead to any compromise results, global crises occurred.

In today's world mostly the dialogue between the individual and the state is used to strengthen legal relations, improve the quality of citizens' life and develop a stronger state

\footnotetext{
*Corresponding author: kapustina@bsu.edu.ru
} 
apparatus that is able both to provide people with various benefits and to be a strong participant in world politics.

First of all, it should be understood that in this context a dialogue is not considered as a conversation between two or more actors, but as a long negotiation process aimed at establishing partnership and strong ties. The subjects of a political and social dialogue seek to achieve mutual understanding and to gain mutually beneficial results in their activities, the achievement of which is a priority. However, it is a rather complex process due to taking into account the interests of all parties involved.

\section{Global trends in development of a dialogue between the individual and the state}

Public dialogue is a type of dialogue aimed at preventing social division and deepening mutual understanding, improving interaction and building constructive cooperation between different strata of society. Such a dialogue is a continuous, constantly developing and improving communication process, which involves representatives of all levels of government, as well as ordinary citizens, both employers and employees. The multilateral and comprehensive nature of a social dialogue involves the objective need to create the atmosphere of trust, openness and readiness to be included in the institutionalized system of information exchange in the society and state. (Zaitsev, 4:9).

When considering the issue of a dialogue between the individual and the state, it should be noted that the dialogue or communication itself has many functions. First and foremost, in democratic states the dialogue accomplishes a political function - the most affordable way of citizens' interaction with authorities - these are elections. Elections are a way of direct participation of politically active citizens in the formation of the political environment of the state, the choice of the course of development of the state, legislation and influence on the government and other authorities through the activities of parliaments at various levels. The Russian legislation provides for a direct dialogue between citizens and representatives of the legislative power, both at the municipal level and at the regional and federal ones. That is, citizens can directly meet with deputies, speak about their problems and ask their questions, in turn, the authorities can contribute to solving the citizens' problems and affect their quality of life for the better - this is an example of a direct dialogue between the society and the government. In addition to the political component, the dialogue can have a social orientation, as it was shown in the example described earlier, and in this context the dialogue can also be civil (public).

One of the main tasks on the part of the state is to attract the maximum number of citizens of the country to interaction with the authorities, to establish a bilateral dialogue aimed at solving common problems and achieving common goals. Despite frequent dissatisfaction with the authorities, citizens often take a passive position and refuse to participate in the events organized by the authorities; they are not easy to get in touch with and often wary of the state and its internal policy. Such cases are one of the most important problems, which requires early solution and, perhaps, a specialized strategy on the part of the state to increase the citizens' loyalty and strengthen its authority.

Building a serious model of a dialogue between the individual and the state requires the involvement of a large number of residents and representatives of various fields. In addition to the abovementioned representatives of the state and municipal authorities, there is a need to involve politicians, deputies of various levels, representatives of public associations, trade unions, representatives of business and non-profit organizations. The closing and the most basic link in this system is represented by ordinary citizens, who mainly pursue their own interests. 
The trend of building and developing a dialogue between the individual and the state has already spread to North America, Europe and the developed countries of Asia. In the states under consideration, the level of citizens' distrust to the power, both to people and the state apparatus and its representatives, is reducing significantly. There is the understanding of the need for competent interaction and achievement of common goals, expansion of the public sphere, involvement of citizens in politics and governance and strengthening of civil society.

In the states, which are already involved in building an effective dialogue between the individual and the state, the solution to this problem primarily faced with the problems of a liberal model of democracy. In this model ordinary people, only as an electorate, participated in elections and formed, thanks to the electoral procedures, a group of elites that represented the interests of citizens. This group of elites often just lobbied for their own interests at the state level, and the general public had no access to participation in the government's activities.

In the states of Europe, North America and East Asia under consideration, the government acts upon similar models. The authorities apply the principles of a participatory democracy, in which citizens not only take part in elections, but also directly participate in the discussion of important state decisions, become initiators and assistants in the implementation of many state projects, are able to express dissatisfaction or support the activities of authorities through fully legitimate methods (meetings, referendums). In some states PR technologies are extensively used in state and municipal governance, which allows establishing contacts with the citizens and showing them the possibility of their participation in the government of a state. GR-management is also becoming popular government agencies together with political parties and business corporations create specialized structures that allow citizens to take a direct part in state activity; the citizens often have a more important status than the initiators of this activity on the part of the authorities. These technologies make it possible to bring the dialogue between the individual and the state to a potentially new higher level. Citizens can initiate joint activities with the authorities, evaluate and control the state policy in solving social problems and issues, involve more citizens in joint activities and strengthen important relations between the state and the society.

Modern interactive media and specialized online resources are becoming a worthy alternative to the existing sources of the government's influence on citizens. Considering the fact that such influence was often exclusively authoritarian and dominant over the public, the Internet has become the key to brining to an end the government's monopoly on information dissemination and opening new ways of effective interaction. In the countries of North America, Europe and East Asia under consideration, innovative communication processes have directly contributed to enhancing the dialogue between the individual and the state, establishing positive communication and involving citizens in joint activities.

\section{Dialogue between the individual and the state. Russian experience and problems}

When we consider the development of social dialogue in the Russian reality, everything looks incredibly complex and unrealizable. The end of XX and beginning of XXI centuries saw formation and strengthening of power in our country. After the severe upheavals of the $1990 \mathrm{~s}$, the state through trial and error assorts the best options for the governance, application and regulation of legislation, creation of wealth and comfortable conditions for citizens. In those times none of the representatives of the state apparatus thought about attracting citizens to running a nation, increasing citizens' politicking and their involvement in political activities apart from their participation in elections. From the point of view of 
the government, the primary tasks were solved, namely how to keep the power, how to make the people loyal to the state and its actions, how to strengthen the economic and social spheres of the state. No one seriously considered the need to involve citizens in public administration.

In the last decade, we have seen a shift in the course of public administration towards interaction with the citizens and the public. The Russian Federation the projects related to the technology of "open government" and "electronic state" are being developed; they provide direct participation of citizens in the activities of the state and municipal government. With the development of online technologies, implementation of joint activities and building of a dialogue between the individual and the state are becoming more accessible.

Despite the serious steps taken by the government, most scientists believe that in modern Russia everything looks different in comparison with other countries. From one point of view, the state is conscious of the need to strengthen civil society and to build a dialogue between the individual and the state. On the other hand, the processes of involving citizens in the government's activities are carried out under the strict control of this very power; they become as formal and bureaucratic as possible, which dramatically reduces the citizens' interest in such joint activities. Considering this issue in more detail, we can conclude that the citizens, who are involved in the activities of state or municipal authorities, simply become an element built into the vertical structure of the power of these very authorities. This creates a negative impact in the process of building a constructive dialogue, as it blocks the possibility of creativity and a fresh look on the part of ordinary citizens. As a result, what our state seeks - a partnership and equal dialogue - becomes unattainable due to the need to build a horizontal system of interaction, where each subject is equal to another, and the vertical system is increasingly strengthened.

Unfortunately, this trend of removal of the state from the general public inevitably puts off the development of a strong civil society in our country. The organizations, which are created by the authorities with the purpose to regulate the issue of a dialogue with the state, contribute to the establishment and strengthening the dialogue, often do not carry out the simplest and most important function - taking into account the views of ordinary citizens. They only pursue the interests of the officials and report to their founders.

What is the paradox of these problems and why are such barriers created in modern Russia when establishing an effective dialogue between the individual and the state? Despite the fact that the need to create and develop a constructive dialogue between the individual and the state in Russia is spoken about by senior government officials and representatives of the public, the importance of building such a dialogue is emphasized by many prominent political scientists and sociologists, the process of developing and enhancing the dialogue is in stagnation.

First of all, the slowdown in the development of a dialogue between the individual and the state in modern Russia is due to the lack of the necessary legal and regulatory framework and the lack of rigorous research in this area in the field of political science and sociology. One of the first scientists, who paid attention to this issue, was the doctor of political sciences S.P. Potseluev: "Paradoxically, in Russia the issue of conceptualization of the political dialogue is not so much approached by political scientists as by their colleagues from related fields of knowledge: philosophers, linguists, sociologists, media scholars." (Potseluev, p.29) In the process of studying this topic, it is common that religious people also note the importance of building a meaningful and effective dialogue between the individual and the state and are ready to act as mediators and assistants in establishing such interaction. This can be supplemented by a huge number of specialists from other fields who can provide direct or indirect support for the establishment of a constructive dialogue between the individual and the state. 
As a result, we realize that, despite many existing opinions in the field of interaction between the state and the society, political science in Russia leaves the possibility of building a dialogue between he individual and the state without due attention and deep practical research, which can change the course of events. Despite the fact that the importance of building an effective, communicative dialogue between the individual and the state is emphasized by almost every political scientist, in practice we get the studies, in which the issue of "Dialogue between the individual and the state" remains being studied only on the surface, from a theoretical, often isolated from the general public, point of view, and has no clear practical recommendations either for the authorities or for the citizens.

To solve these problems, it is necessary to delve into the causes and difficulties of building a constructive dialogue between the individual and the state.

Obviousness can be defined as the first problem. "At first sight, occurrence and commonness of the dialogue are so intuitively true and obvious that it sometimes leads to a view of dialogue as something not worthy of special study," writes philosopher and logician (Skripnik, p. 4). So it turns out that, if all scientists emphasize the need to build such a dialogue, the state needs it, and citizens simply demand it - all parties are interested, therefore, the process does not require any deeper research, opinions and improvements.

The very building of a dialogue, as an opportunity for interaction, is quite difficult, if the subjects should be the individual and the state. Moreover, additional subjects - political parties, representatives of the Church, representatives of the business community and nonprofit organizations and others - can enter into such a dialogue. So, when we consider the dialogue in this way, we understand that the dialogue is a part of linguistics. First of all, it solves political and social issues, which are the most important for both citizens and the state. The economic sphere cannot remain without attention. Taking into account the fact that citizens are not ready to solve public problems competently, they need the help of philosophers and psychologists. To apply modern technologies of interaction it is desirable to involve PR and GR-managers. As a result, the whole system of a dialogue between the individual and the state becomes a large-scale problem, the solution of which requires a systematic and effective approach of its participants. We need a lot of human resources and a lot of theoretical and practical research for the actual preparation of such a structure.

Another issue is the existing political mood in the country. Given the parties' competitiveness and the need to fight for the power during election campaigns, it is often difficult to build a dialogue, as it involves the process of uniting political forces and should completely eliminate their competitive attitude to each other.

In fact, the political system should look both competitive and with possible concessions, which can be expressed in the form of public dialogues. In Russia the complexity of the integration of a dialogue between the individual and the state is related to the relatively young age of the state power and the political system. Definitely, after the collapse of the Soviet Union it took a huge amount of time and effort to change the legislation and rebuild the policy according to the modern capitalist society; none of the scientists cannot still confirm that the transformation process is complete. So, it is necessary to implement a constructive dialogue between the individual and the state in such a complex political and administrative system, which currently exists in modern Russia.

Considering the existing problems, modern political scientists, philosophers and sociologists need to start suggesting solutions, developing theoretical, methodological and practical concepts to build a dialogue between the individual and the state. In their turn, the representatives of the state and municipal authorities should make contact and create preconditions for an open dialogue with scientific men to make it possible to continue working in this direction and to attract the general public to joint activities.

One of the reasons for the need for the rapid development of the system of building a dialogue between the society and the government is the interest of all parties to this process. 
For example, when building a dialogue, the government will receive an additional tool to stabilize the society, it will be able to solve the people's problems more quickly, thereby reducing the level of discontent. He citizens will reach a greater level of satisfaction with the activities of the state and political parties, and, for example, the opposition will be able to influence the actions of the government through the existing model of civil dialogue. Definitely, building a constructive dialogue between the society and the state will increase the level of moderation in the country, it will help to smooth out conflicts and increase the influence of the government. An effective dialogue between the society and the government can replace the existing negative ways of expressing their will on the part of citizens (political meetings, protests, etc.) with more effective and productive methods of interaction between the state and the society (discussions, negotiations, civil control, etc.).

Studying the extensive material on this issue, it is possible to identify perhaps the most essential problem: how, in fact, can a relation between the individual and the state be established? This problem concerns all the participants of interaction between the society and the government. From the point of view of the state, the serious difficulty is the lack of tools and mechanisms of interaction with citizens. How is it possible to establish communication in order to know the real opinions of ordinary citizens? How is it possible to involve these citizens in joint activities? How is it possible to convince them that the opinions, which they will express in these dialogues, will be heard and sorted out, and expert assistance will be provided or they will be applied in public administration? Each of these issues requires detailed study: training of specialized personnel, extensive advertising campaign to inform the population, preparation of specialized sites and many other factors that affect the possibility of creating and developing a constructive dialogue between the individual and the state.

\section{Conclusion}

Civil dialogue between citizens and the state, which is built with the help of various communication tools, is one of the most effective ways of interaction between the government and the society. Building a model of effective dialogue between the individual and the state is one of the priorities for the authorities and the public in any legal state. The states of North America, Europe and East Asia successfully use the technologies of civil dialogue to maintain a favorable environment in the state. Establishing and strengthening of civil dialogue between the individual and the state in the Russian Federation is accompanied by a number of serious problems associated with the lack of practice-oriented and applicable scientific works, the lack of training of representatives of state and municipal authorities, low politicking and community commitment of citizens and insufficient preparation of material and technical base. Also, to develop effectively the principles of building a dialogue between the individual and the state in the government activities, it is required to use modern technologies aimed at communication with the public: PR and GR-management, creation of specialized online resources and global PR campaign. Besides, to create an effective model of interaction between the society and the state, it is necessary to eliminate or reform the existing formalized organizations, which are responsible for communication with citizens, but, in fact, they only report to the authorities for their activities. Summarizing the materials of the article, it is possible to emphasize that for building a dialogue between the individual and the state, the following is necessary:

- Involvement of specialists of various profiles (political scientists, philosophers, sociologists, linguists, anthropologists, psychologists and other professionals) to train qualified personnel among authorities' representatives;

- Preparation of theoretical, methodological and practical recommendations to carry on an informal, constructive dialogue between the individual and the state; 
- $\quad$ Promotion of the civil dialogue in society;

- Introduction of really effective technologies of interaction and facilitation of a dialogue between the individual and the state.

\section{References}

1. V.G. Fedotova, A.F. Yakovleva, Philosophy and culture, Science and modernization, 9, 61-72 (2014)

2. A.G. Komkov, Human resources as the main category of the power (RAGS, Moscow, 2014)

3. S.A. Ovsyannikov, Motivation of public participation in authorities' activities (Municipal government, Moscow, 2013)

4. S.P. Potseluev, Dialogue and quasi-dialogue as a form of discursive interaction in political practice of the communicative society (Rostov-on-Don, 2010)

5. O.V. Shinyaeva, I.G. Gonoshilina, Civil society in Russia: condition, trends, prospects (Ulyanovsk State Technical University, Ulyanovsk, 2012)

6. A.N. Shirokov, Organizational forms of public participation in the activities of executive authorities (Municipal government, Moscow, 2014)

7. K.D. Skripnik, Philosophy. Logic. Dialogue (JuFU, Rostov-on-Don, 1996)

8. A.V. Zaitsev, Dialogical model of public relations: M. Kent and M. Taylor, Modern scientific researches and innovations, 7, 12-17 (2013)

9. A.V. Zaitsev, Political $P R$ and dialogical model of public relations $R$. Pearson, Humanities research. Scientific and practical journal, 7, 23-24 (2013)

10. A.V. Zaitsev, The state and civil society: the lack of dialogue Humanitarian scientific researches, 8, 4-9 (2013) 